\title{
Identidade dos trabalhadores na confluência entre o global e o local: o caso da região do Complexo do Alemão
}

\author{
Ozias Jesus Soares*
}

Resumo: Entendemos que a conformação do fenômeno das metrópoles e megalópoles é a expressão contraditória do avanço do capitalismo de marca industrial. No final do século XX assistimos a novas ordenações na esfera do capitalismo considerando a incorporação de novas tecnologias e a globalização da economia. Permanecem, todavia, as marcas do abismo sócioeconômico que separam pobres e ricos no tecido urbano das metrópoles brasileiras. As áreas favelizadas da cidade do Rio de Janeiro nos informam sobre tal fenômeno. Diante disto, cabe colocar em relevo as formas de inserção no mundo do trabalho e da sobrevivência das populações dessas áreas. O texto informa sobre a realização de uma investigação sobre as transformações na esfera do trabalho e da produção ocorridas no subúrbio da Cidade do Rio de Janeiro, em especial os bairros no entorno do Complexo do Alemão - local de moradia de cerca de meio milhão de habitantes. Queremos discutir o desenvolvimento e transformações da cidade em efervescente pólo industrial ao longo do século XX e a contribuição do mundo do trabalho para a construção identitária tanto de indivíduos como de instituições. Neste sentido, uma questão central emerge aí, a saber: as transformações na estrutura produtiva da região do Complexo do Alemão nos permitiriam falar de um novo ethos do trabalho, conformação de novas identidades e organização dos trabalhadores?

Palavras-chave: Identidade dos trabalhadores; Complexo do Alemão; ethos do trabalho

\begin{abstract}
The identity of the workers between the global and the local: the case of the region of the "Complexo do Alemão"

The phenomenon of megacities reflects the contradiction of the advance of capitalism system. Considering the incorporation of new technologies and the globalization of economy at the end of the twentieth century, we are in presence of new ordinations in the capitalism sphere. However, the socio-economic stigma that separates the poor and rich people in the urban Brazilian cities remain as we can see in the Rio de Janeiro slums areas. Therefore, it is important to analyses the labor world and survival of workers in these areas. This article presents an investigation of the production and work transformations occurred in the Rio de Janeiro suburb, especially in the neighborhoods surrounding the Complexo do Alemão - the space of about half a million people. We wish to discuss the development and transformation of the city as a bustling industrial center during the twentieth century and the contribution of the labor for the construction of identity of both individuals and institutions. In this sense, a central question emerges here, namely: Can we say that the changes in the productive structure in the Complexo do Alemão area brought a new ethos of work and identities?
\end{abstract}

\footnotetext{
" Ozias Jesus Soares é doutorando do Programa de Pós-Graduação em Ciências Sociais da Universidade do Estado do Rio de Janeiro (PPCIS/UERJ).
} 
Keyword: workers identity; Complexo do Alemão; work ethos

A discussão sobre a questão da identidade é abordada por diversos autores e sob diferentes perspectivas de análise. Elias (1994), por exemplo, aponta a localização e gênese histórica dos conceitos indivíduo e sociedade numa relação entre o que chama de “identidade-eu" e "identidade-nós". Para o autor a relação de equilíbrio-desequilíbrio nesses dois conceitos vai se modificando ao longo dos anos e em contextos diferenciados. Informa-nos que na antiguidade havia uma pendência da balança para a “identidade-nós”, no caso do Estado Romano. O pertencimento à família, à tribo e ao Estado era inicialmente considerado na constituição do sujeito. Desse modo, o indivíduo não existia sem o grupo. Destaca que o termo indivíduo (no seu sentido de isolado, sozinho) era desconhecido naquele contexto, explica Elias.

O termo "individual", inexistente no contexto que nos referimos acima, não dizia respeito a seres humanos, mas a coisas indivisíveis. Postula Elias que o termo "individual" como se referindo a uma pessoa alça este peso quando num determinado estágio do desenvolvimento social e de comunicação as pessoas passam a perceber a necessidade de singularidade quando comparada às demais.

Em relação ao conceito de sociedade, Elias coloca que até a Segunda Guerra Mundial o conceito cabia às sociedades organizadas como Estados ou ainda como tribos. Declara que à medida que as sociedades vão se complexificando, a posição individual de cada pessoa em relação a um todo também se modifica. Inclui aí a questão da individualização. Destaca que em tempo anteriores a questão do agrupamento de seres humanos atendia à necessidade de proteção contra quaisquer hostilidades externa $\mathrm{e}$ que esses mesmos grupos eram pouco numerosos. Uma pessoa sozinha teria poucas chances de sobreviver às intempéries e perigos existentes. Temos então que o agrupamento responde a uma necessidade de proteção e, desse modo, de distinção. Uma perspectiva a ser discutida, portanto, é que a questão da identidade remete-nos à criação do estado-nação: difunde-se a idéia de uma única cultura organizada enquanto modelo de identidade nacional.

No caso brasileiro, por sua extensão, características demográficas, ocupação do solo e os diferentes grupos que se formaram e fundiram-se aqui nos últimos séculos, 
temos um tecido social múltiplo que nos impõe, em certa medida, a falar de "identidades" no lugar de identidade. A dinâmica da globalização da economia, em especial através compressão espácio-temporal tem contribuído para a revisão das identidades nacionais (Harvey, 2003). Desse modo, surgem identidades culturais em transição, que resultam de diálogos entre diferentes tradições culturais e trocas presentes no mundo globalizado. Hall (2000) vai chamar este fenômeno de novas identidades ou identidades híbridas.

Quando recortamos o nosso objeto para falar de grupos de trabalhadores, em relação à vida local, participação comunitária, constituição de instituições locais, gerenciamento das oportunidades e recursos sociais, dirigimos a nossa atenção a uma parte constitutiva da identidade que teria, assim, um componente mais geral nucleado pelo mundo do trabalho.

Estamos convencidos, assim, que falar de identidade atualmente é embrenharmos em um campo conceitual polissêmico e complexo. Trabalhamos aqui inicialmente com a concepção de que o espaço de vida dos trabalhadores é também o espaço de manifestações múltiplas de participação, cultura, expressões de valores, representações, projetos etc. É ali, e a partir dali, que estabelece redes de sociabilidade, de referências, amplia recursos e oportunidades, define ações políticas, participa de experiências significativas junto a outros trabalhadores. Conforme Cabral (1999) a identidade humana é configurada de acordo com um complexo de relações, onde a inserção num contexto social faz com que haja incorporação de atitudes e valores de acordo com a troca com outros sujeitos vivos e mortos, além do engendramento das relações sociais das quais os meios culturais que interpelam o sujeito o classifica socialmente.

Em meio a isto, é preciso considerar ainda que as identidades dos trabalhadores podem acumular valores e referências produzidas por grupos que detém o poder material e querem imprimir um conjunto simbólico sobre os demais. Trata-se, portanto, da conquista da hegemonia. Gramsci nos adverte que "toda relação de 'hegemonia' é necessariamente uma relação pedagógica" (1978, p.37). Sendo assim, o lugar da hegemonia será o de legitimar concepções e identidades alheias ao mundo e às necessidades apresentadas pelo conjunto dos trabalhadores. Na concepção gramsciana, “o Estado é todo o complexo de atividades práticas e teóricas com as quais a classe dirigente justifica e mantém não só o seu domínio, mas consegue obter o consentimento 
ativo dos governados" (Gramsci, 1980, p.87).

Temos aqui concepções diferentes de identidades que, todavia, não se excluem: uma primeira enquanto construção cultural, identificação com um grupo, conjunto de valores, comportamentos, hábitos, gostos etc.; uma outra, definida enquanto um projeto identificatório produtor de alinhamento a um pensamento hegemônico. A primeira estaria ligada em nossa concepção ao fortalecimento de instituições políticas locais e de participação comunitária. A segunda caminharia na direção da produção de consenso, da criação de um ethos que se pretenda de uso geral. Nesta última acepção, concordando com as idéias de Rummert (2004), faz-se necessário

Construir um conjunto de valores, normas de comportamento, formas de representações do mundo e padrões de socialização que assegurem, ao Capital, que o trabalhador estará afetivamente comprometido com a produtividade e a competitividade da empresa (p.18).

E que, portanto, nesta direção, o papel da hegemonia será o de impor profundas mudanças que, segundo a autora, referem-se não apenas à concepção de mundo de cada trabalhador, mas ao conjunto da sociedade. Para Rummert (idem),

Tais transformações implicam a formação de um novo ambiente cognitivo e afetivo que transcenda o âmbito da empresa e se irradie pela totalidade social e, sobretudo, a difusão do 'ethos empresarial' (p.18).

Nesta perspectiva será importante perceber que as transformações e reordenações do mundo do trabalho incidem sobre as formas e expressões de vida dos sujeitos, na medida em que a partir dele retiram sua subsistência, constroem subjetividades, relacionam-se com outros sujeitos e participam da vida local.

Podemos destacar no quadro social vivido nos últimos anos que o pauperismo, desemprego crescente e - a partir da quebra de fronteiras e proteção nacionais - a própria fuga de empresas de uma região para outros cantos do planeta, termina por configurar um novo desenho no urbano e que merece um maior entendimento das relações que daí emergem.

Entendendo os fenômenos a partir de uma totalidade concreta, insistimos na necessidade de se pensar as conexões entre as alterações no mundo do trabalho - e seus resultados - com as questões da explosão demográfica, favelização e aprofundamento das desigualdades sociais e seus desdobramentos na construção e consolidação da identidade dos trabalhadores. 
A centralidade que aqui estamos imprimindo ao trabalho enquanto nucleador da existência e capaz de (re)configurar identidades dos trabalhadores parte de uma concepção ontológica do trabalho humano, na medida em que a produção dos meios de existência refere-se à própria produção e reprodução da vida material (Marx, 1987). Na defesa desta concepção, Frigotto (1983) expressa o trabalho enquanto "uma relação social que os homens estabelecem na produção de sua existência”, e completa:

\footnotetext{
O trabalho enquanto um processo em que participam os homens e a natureza onde o ser humano com sua própria ação impulsiona, regula e controla seu intercâmbio material com a natureza como uma de suas forças (...) e atuando assim sobre a natureza externa e modificando-a, ao mesmo tempo modifica sua própria natureza (p.39).
}

Nesta perspectiva, tratar das questões que envolvem a produção do espaço e suas dinâmicas coloca-nos diante do exercício de pensar a constituição de um modelo de trabalho e de suas relações que norteiam a experiência e sobrevivência no mundo contemporâneo. As transformações pelas quais passaram o mundo da produção, neste sentido, também alavancam uma série de outras mudanças (Harvey, op.cit.; Wood, 2001; Sennett, 2000).

Se no contexto dos países desenvolvidos as transformações no mundo do trabalho contribuíram para a elaboração de identidades individuais e coletivas que se expressam no campo da organização e participação política, no caso brasileiro, embora a reboque dos países centrais, acabamos sorvendo os efeitos de modo diverso e perverso.

Diante disto, interessa-nos a investigação no plano do real sobre as transformações na esfera do trabalho e da produção ocorridas/percebidas na chamada Zona da Leopoldina, em especial a que compreende os bairros da Penha, Olaria, Ramos, Bonsucesso, Inhaúma, Higienópolis, Maria da Graça, Del Castilho e Benfica. Colocamos a necessidade de uma investigação que relacione a questão da precarização das relações de trabalho e a pauperização de grandes contingentes populacionais e a organização e identidade dos trabalhadores.

Percebemos que, no conjunto da vida social, existem elementos que constituem e reconstituem as identidades dos trabalhadores. Nesta direção surgem novas estratégias de vida e sobrevivência, organização e reorganização da vida comunitária frente ao momento em que se (auto)constrói uma das áreas mais densamente habitadas na cidade do Rio de Janeiro, palco de ações e omissões das políticas públicas nas últimas décadas 
do século XX.

Em relação ao lócus espacial desta pesquisa, qual seja, os bairros no entorno do Complexo do Alemão, dados empíricos nos mostram que (1) na medida em que houve um deslocamento das empresas da região para outros lugares na cidade ou no estado, um novo dinamismo em relação aos trabalhadores também se impôs; (2) houve um visível crescimento das economias populares na região, ao que compreendemos como um recurso primeiro de sobrevivência.

Caberá ainda incorporar aqui discussões com respeito ao estímulo às diversas formas de empreendedorismo no Brasil que caminha lado a lado com uma política repressiva e estigmatizante das economias populares; ou seja, a exemplo do Rio de Janeiro na atual gestão municipal, a expulsão de ambulantes e pequenos comerciantes no Centro e subúrbio, sob a rubrica da "ordem urbana" (Operação Choque de Ordem) obscurece a necessidade de se pensar alternativas à altura das demandas por trabalho e geração de renda que estão visivelmente postas.

No intuito de compreender as transformações visíveis no espaço em questão, cabe dizer que o Rio de Janeiro possui uma história de organização do trabalho e de sua estrutura produtiva bem peculiar. Diretamente ligado a isto, temos a história da urbanização sempre conflitante em nosso contexto. Em 1890, um ano após a instalação da República, a população dos cortiços no Rio de Janeiro era de 100 mil habitantes (Gonçalves, 2007). Identificados como locais insalubres e alvo de toda política de cerceamento e remoção, os cortiços abrigavam uma população misto de ex-escravos e trabalhadores braçais. As diversas formas de resistência não faltaram a estas populações em diversos momentos, como o movimento conhecido como Revolta da Vacina em 1906 (Carvalho, 1987). As terras pouco valorizadas pela população mais abastadas e pela especulação imobiliária eram alvos da ocupação pela população que afluía à cidade em busca de um lugar na nascente indústria da capital federal. Soma-se a isto que a renda das famílias pobres trabalhadoras na cidade do Rio de Janeiro no contexto do início do século XX acabava estabelecendo rígidos limites para uma ocupação regular do solo. Contraditoriamente - uma cidade dependente de mão de obra barata para efeito da acumulação de capital - destacamos que não faltaram àquele momento histórico variadas formas de cerceamento do crescimento das áreas ocupadas pela população trabalhadora.

Portando, além dos cortiços nas áreas centrais onde habitavam os trabalhadores, 
os morros que cercavam essas mesmas áreas acolhiam uma população que construíam seus casebres tendo em vista a proximidade com o trabalho. Essas construções não eram conhecidas como "favelas" propriamente até o final do século XIX, tendo em vista que este termo (Favela) nomeava apenas o Morro da Favella (atual Morro da Providência). No entanto, as características similares de outras ocupações nas franjas da cidade acabaram sendo também denominadas por "favela" .

Apenas no texto do decreto 6.000/37 denominado Código de Obras do Distrito Federal, do presidente Getúlio Vargas, aparece o termo "favela" pela primeira vez. Segundo Gonçalves (2007), "O artigo 349 deste código, primeiro texto jurídico a empregar o termo 'favela', consolidou a associação sistemática entre favelas e ilegalidade, influenciando, profundamente, as políticas urbanas em relação a estas durante décadas". Concordando com as palavras de Gonçalves (op. cit.), a moradia na favela 'permitia, muitas vezes, a redução dos custos 'transporte' e 'moradia' na reprodução da mão-de-obra, o que reforçava a espoliação das classes populares no âmbito das relações de trabalho propriamente ditas" (p.14).

Expulsos do centro da cidade, a população trabalhadora ora ocupou os morros no entorno ou se deslocou para áreas suburbanas periféricas. Na década de 1920, conforme aponta Abreu (2006), tínhamos uma região suburbana com efervescentes atividades de exploração do solo, indústrias, transporte e comércio. Como dissemos acima, a fase pós1930 acelera os investimentos nesta área e a cidade amplia suas vias para a periferia.

O decreto 6000/37, citado acima, criava um novo zoneamento da Cidade e determinava que o centro e a zona sul - tradicionais espaços fabris - passassem a ser áreas estritamente residenciais (Abreu, 2006). Desse modo, o adensamento do subúrbio imediato (Periferia imediata) ${ }^{2}$ foi uma conseqüência do deslocamento das indústrias ora para as regiões industriais recém-criadas ou para outros estados do Brasil, dentre eles São Paulo.

No Rio de Janeiro, a região que mais se destacou enquanto pólo fabril-industrial foi a chamada zona suburbana I que englobava as regiões do Engenho Novo, Méier, Inhaúma, Piedade, Irajá, Madureira e Penha (Dados do censo demográfico de 1950, apud Abreu, op. cit.)

Mesmo com as determinações de zoneamento definidas pelo Decreto acima, muitas áreas próximas a morros íngremes e áreas alagadiças foram ocupadas pelas populações mais pobres a partir da autoconstrução. Em 1950 já havia um contingente de 
cerca de 170 mil moradores em favelas no Rio de Janeiro. Entretanto, mesmo com os números gritando por uma solução pública, os diversos planos urbanísticos da cidade deixaram de fora o tratamento a esta população uma vez que desde o Decreto 6000/37 já eram considerados, no plano jurídico, a partir da noção de ilegalidade ${ }^{3}$.

É preciso destacar nesta discussão que, com o surto de crescimento induzido pela Primeira Guerra Mundial, o país passa a ser um importante pólo produtor e exportador - o que deixou a burguesia industrial em posição de destaque, impondo, com isso, rápidas alterações no espaço da cidade, no zoneamento e alocação fabril-industrial e, consequentemente, nos espaços de moradia das populações trabalhadoras. A combinação crescimento-desenvolvimento com a inadequação viária e habitacional da cidade acabou por pressionar a elaboração de planos que organizassem o traçado urbano.

Em relação à área que recortamos nesta pesquisa, enfatizamos num primeiro olhar sobre este real, que nas últimas três décadas do século XX a região ganhou contornos diversos, passando desde a fuga de grandes empresas industriais até a aglomeração de contingentes populacionais nas áreas já favelizadas desde décadas anteriores ao período em questão ${ }^{4}$.

Nas décadas de 50 e 60 - período em que o país ganha novos contornos a partir da etapa conhecida como nacional-desenvolvimentismo, a região ganhou status de pólo fabril-industrial atraindo uma população trabalhadora que passou a ocupar terras pouco valorizadas até então (Fraiha e Lobo, 2002). Não apenas pouco valorizadas pela especulação imobiliária, como ainda distante de uma política habitacional que previsse o atendimento à população trabalhadora.

Um dos ícones do que estamos tratando é a extinção da então indústria Nova América, grande empresa do setor têxtil, hoje transformada em um shopping center ${ }^{5}$, no bairro de Del Castilho. Outro grande ícone industrial é o Curtume Carioca (Penha) que empregava um enorme contingente de trabalhadores suburbanos (Fraiha e Lobo, op.cit.). Ainda outros exemplos, dentre tantos que poderia aqui listar, é a indústria têxtil Sayonara-Poesi e a Fabricada Coca-Cola (ambas na Estrada do Itararé), conjuntos arquitetônicos que recentemente foram invadidos pela comunidade no entorno a fim de retirar o que fosse possível para uso próprio ou venda do que ficou das empresas já abandonadas. Atualmente o espaço dessas fábricas e galpões dará lugar ao projeto ambicioso do Programa de Aceleração do Crescimento (PAC) que envolve construção 
de unidades habitacionais, escolas, postos de saúde, áreas de esporte e lazer e um teleférico que ligará algumas favelas e bairros da região.

Cabe, portanto, indagar: como se percebem os moradores de uma das áreas mais populosas do Rio de Janeiro e do Brasil diante das transformações do mundo do trabalho? Como sobrevivem e (re)organizam a vida e as estratégias de sobrevivência considerando um quadro de precarização das relações de trabalho? Quais as novas articulações que as instituições de formação - com destaque para a escola - e de participação políticas precisam realizar num contexto de reordenações nas perspectivas de trabalho e geração de renda?

Diante do exposto até aqui, percebemos o quanto este primeiro olhar em volta nos motiva a questionar sobre as determinações do fenômeno do mundo do trabalho sobre o real. Cabe questionar, por exemplo, algumas elaborações ideológicas radicadas no senso comum - nem por isso criadas por ele - e divulgadas pela mídia hegemônica, quanto ao aumento do banditismo na região como fator de fuga das empresas da região do Complexo do Alemão. As causas dessa fuga estariam no crescimento das favelas, divulgam. Aqui convém assinalar que se de fato houve um elevado crescimento populacional no entorno desde a década de 70, favorecendo a expansão das favelas, não é possível categoricamente afirmar que este tenha sido a causa para a fuga das empresas. Tais construções ideológicas precisam ser analisadas sob o prisma de uma investigação coerente com um método histórico. No conjunto da pesquisa e nos questionamentos que a instala, precisamos perceber uma série - ao menos inicial - de aspectos aí circulantes, indicando a relevância do tema, a saber:

- As relações entre a decadência do emprego assalariado nesta região e o crescimento de iniciativas da economia popular nas comunidades do "Complexo do Alemão" são elementos apontados num quadro geral por outras pesquisas realizadas (Tiriba, 2001; Tiriba e Picanço, 2004). Certamente tal crescimento não é prerrogativa desta região do subúrbio do Rio de Janeiro; antes, expressa uma tendência geral no contexto das economias dos países da periferia do capital, consubstanciado pela chamada reestruturação produtiva (Harvey, op.cit.);

- No período histórico que recortamos para efeito de análise na pesquisa (19702000), houve um crescimento populacional da região e investimentos em infraestrutura, saneamento básico e urbanização das favelas. Tais iniciativas foram de um lado, resultados da organização das associações de moradores da região e suas lutas por 
um espaço mais digno de sobrevivência, como ainda fruto de ações pontuais de governos populares instalados no Rio de Janeiro a partir da década de 1980. Talvez possamos dizer que os investimentos em urbanização e saneamento básico carregariam em si uma visão "social" da favela, qual seja, a contenção dos mais pobres naquela região. Muitos desses investimentos, construídos ao toque de eleições municipais e estaduais, vem mostrando, na prática, sua baixa qualidade, inadequação e a falta de uma garantia de manutenção permanente;

- A crise do trabalho coincide com a crise da escola (ou a crise do trabalho é também a crise da escola). Mesmo não sendo característica percebida unicamente nesta região, ao conjunto de aspectos produtores da desigualdade soma-se a degradação das escolas desta região do subúrbio. Degradação esta impressa na baixa qualidade do ensino, na interrupção do calendário letivo tendo em vista eventos violentos que passam a se tornar uma regra antes de ser uma exceção, destruição dos prédios escolares, entre outros. O que nos parece ainda num primeiro momento é que a escola do trabalhador (em geral, a educação de jovens e adultos que ocorre nos cursos noturnos) caminha na mesma direção, com o agravante de ser uma escola imediatista para inserção ou permanência no "mercado de trabalho" assalariado. Na elaboração de identidades, a escola emerge como um elemento especial, na medida em que graus de escolaridade representam inserção no mundo do trabalho de forma mais qualificada. Entretanto, como fica a escola diante da reconfiguração das identidades em uma época marcada por incertezas e novas demandas?

- Girando em torno do objeto central desta pesquisa - as transformações no espaço como resultados de processos desiguais no mundo globalizado - há que considerar o local em suas múltiplas articulações (e dependências) de um contexto mais amplo (social, econômico, político, educacional). Ou seja, está posto uma necessidade de aprofundar um estudo em torno das perdas do mundo do trabalho assalariado em relação com as demais transformações por que passou a configurar esta região no momento atual (Godinho, 2008). É possível apontar estas perdas? Quais seriam as principais transformações? Como o espaço do contraditório impõe novas formas de se pensar o mundo do trabalho e a emancipação humana? Elegemos o trabalho como categoria central na análise social (Antunes, 1999). Mesmo que o trabalho manifestado/materializado aí se apresente como alienado, subserviente, assalariado, expropriador - é através dele que se coloca a possibilidade do descortinar a luta 
emancipatória, considerando o aprofundamento de suas contradições;

Destaca-se que não focamos nossas análises em uma relação causal mecânica e que, portanto, atuar sobre tais causas traria como resultado o "El dourado" novamente à região. Nossa hipótese é que não teria sido unicamente a perda da vocação fabrilindustrial da região que teria fundado o cenário de favelização e precariedade visto hoje. As relações sociais que aí se produzem elencam determinações de várias ordens que dão corpo a uma situação cada vez mais agravada pelo cenário de aprofundamento das desigualdades urbanas (Davis, 2006). Ao contrário do que tem sido divulgado por alguns autores, é preciso questionar as concepções do "abandono" do Estado na região. Que tipo de abandono? Por um lado, podemos compreender que a configuração de um Estado liberal, ancorado nas relações de mercado, especialmente no caso latinoamericano, a situação das classes populares acha-se em permanente processo de fragilização e vulnerabilidade, o que pressupõe um relativo abandono na efetivação de políticas sociais (Laurell, 1995; Soares, 2002). Por outro lado, mesmo de dentro de uma política que podemos chamar de superficial por não tocar as questões centrais da produção de abismos de desigualdades, cabe dizer que nas décadas de 1980 e 1990 assistimos a um crescente número de iniciativas voltadas à urbanização desta região (como exemplo o Favela-Bairro, da Prefeitura do Rio), instalação de equipamentos públicos de saúde, saneamento básico, rede elétrica, ampliação da oferta escolar, programa de distribuição de água gratuito, gratuidade no transporte público, livro didático, merenda escolar, uniforme, programas de complementação e aumento da escolaridade, programas sociais de complementação de renda, bolsa-escola etc.

Nosso foco será o universo do trabalho e suas relações dentro do contexto das dinâmicas urbanas e (re)produção de desigualdades no subúrbio do Rio de Janeiro e da configuração da identidade dos trabalhadores desta região. Neste emaranhado, é preciso compreender a dimensão organizativa e participativa da vida local. O período que recortamos para efeito do estudo trata-se de um momento central em nossa análise. As três últimas décadas do século XX não são apenas efervescentes do ponto de vista das mudanças globais no plano social, cultural, político e econômico, mas podemos perceber como as marcas deste processo histórico se fazem sentir em escala local. Portanto, uma primeira hipótese que aqui expomos diz respeito às transformações globais no plano político e econômico que repercutem em uma região específica, principalmente quando esta tenha historicamente se destacado enquanto importante pólo 
produtivo fabril-industrial. Queremos nos deter, portanto, nesta pesquisa, às transformações que caracterizam o espaço urbano a partir da esfera do trabalho; e, a esfera do trabalho e da produção enquanto elementos configuradores e reconfiguradores da identidade dos trabalhadores residentes nesta região.

Assim posto, temos como objeto da pesquisa uma investigação das relações entre trabalho, dinâmica urbana, configuração de identidades dos trabalhadores e o conseqüente aprofundamento de desigualdades. Neste sentido, nosso objetivo geral pretende analisar as transformações ocorridas nas décadas de 1970 a 2000, inclusive, numa região do subúrbio do Rio de Janeiro, procurando entender as articulações entre um contexto global de relações de trabalho incidindo sobre o local com efeitos sobre a identidade dos trabalhadores e a pauperização urbana.

Desse modo, elencamos os seguintes objetivos da pesquisa:

1. Investigar as novas configurações na esfera do trabalho e estratégias de sobrevivência da população do entorno do Complexo do Alemão.

2. Analisar como se constitui a identidade dos trabalhadores desta área, considerada em meio a um quadro de pauperismo urbano, fragilidade de políticas públicas e precarização das relações de trabalho;

3. Apresentar como se constituiu a população da fração do subúrbio do Rio de Janeiro, em destaque para a área recorte desta pesquisa;

4. Identificar a ascensão dos bairros no entorno do Complexo do Alemão enquanto uma região fabril-industrial, bem como a decadência e transformações na esfera da produção e do trabalho que incidiram sobre a região;

5. Compreender a história do espaço urbano do Rio de Janeiro e, nele, o desenho do cenário industrial na cidade.

A questão urbana que produz os chamados bolsões de pobreza e regiões favelizadas não é algo novo ou a sua construção não é algo estritamente de responsabilidade da população que ali aflui. É preciso pensar a favela a partir de um olhar de totalidade em que as partes encontram-se em estreita conexão com o todo e o todo se divisível expressa, na verdade, em suas partes, aquele mesmo todo (Kosik, 2002). Estamos trabalhando com a região do Complexo do Alemão enquanto o espaço denso (e complexo mesmo!) de vida dos trabalhadores. Persistimos na necessidade de um novo olhar sobre o urbano e suas contradições.

Compreendemos que a participação ativa da sociedade civil deve compor uma 
agenda dentro de um contexto de cidadania plena, para além de usos eleitoreiros ou de acumulação de capital, ou ainda de ser objetos de políticas aligeiradas e maquiadoras de plantão. Os mais de um milhão de moradores de favelas do Rio de Janeiro precisam sair da condição de uma "subcidadania urbana" (Kowarick, 1993). Além disso, povoam o tecido urbano projetos pensados não como uma política habitacional e de inclusão social efetiva, mas, como marcas e bandeiras eleitorais de determinados grupos políticos. Tais intervenções acabam não apenas feudalizando as favelas e demais áreas suburbanas, como não atendendo às reais necessidades que acometem as populações favelizadas. O resultado de tais políticas fragmentadas que fervilham em épocas próximas às eleições são a consolidação da desigualdade e segregação urbana e, em última instância, a garantia da legitimidade e a permanência de grupos no poder. Insistimos, portanto, na necessidade do fortalecimento dos sujeitos coletivos, das instituições populares que pensem o urbano em todas as suas dimensões enquanto direito e participação.

Pretendemos, portanto, abranger o objeto em todos os seus aspectos, suas relações e mediações, seu desenvolvimento e automovimento "incorporando a prática humana quer como critério de verdade, quer como determinante prático da relação entre o objeto e aquilo que o homem necessita" (Kuenzer, 1998). Ao longo da exposição de nossas idéias e investigação, buscaremos deixar em evidência por quais caminhos e bifurcações tecemos o movimento do real, na tentativa de chegarmos a novas sínteses no plano do conhecimento e no plano do concreto. O movimento realizado vai desde o lançar luzes sobre o todo caótico, apontado brevemente nas linhas acima para chegarmos à tentativa de desvelar as relações entre a aparência e a essência do fenômeno que produz - e reproduz - a situação de pauperização, no entanto, sem que a realidade da exclusão e das desigualdades sejam sequer tangenciadas. Requer-se, assim, um esforço de partir do "concreto vivido", no nosso caso, expresso através das desigualdades e pauperismo centrado nas relações sociais de produção em uma região especifica do subúrbio da cidade do Rio de Janeiro para apreender as partes que o compõe, analisá-las, e, com isso, produzir os nexos, as relações entre si. Articulando essas partes, pretendemos chegar ao "concreto pensado". Nas palavras de Kosik,

A compreensão dialética da totalidade significa não só que as partes se encontram em relação de interna interação e conexão entre si e com o todo, mas também que o todo não pode ser petrificado na abstração situada acima das partes, visto que o todo se cria a si mesmo na interação das partes (Kosik, 
2002, p.42).

Reconhecemos o imperativo de situar historicamente o objeto, como o fizemos nas linhas acima. Cumpre destacar a forma particular como se constituiu o urbano na cidade do Rio de Janeiro, tendo como nucleador as relações sociais de produção, inicialmente, sem dúvida, sem o caráter industrial que irrompeu a partir do século XX, mas depois com toda a sua força no despontar da segunda metade deste mesmo século.

Queremos dar atenção especial nesta pesquisa, como dissemos, para a centralidade do trabalho e das relações econômicas enquanto instâncias constitutivas da sociedade. Neste sentido, cabe trazer discussões indispensáveis no conjunto da necessidade de compreensão do objeto, tais como a histórica - enquanto produto das relações sociais que os homens entre si estabelecem. Decorre daí que, tanto a historicidade do objeto, quanto as suas relações com o contexto do capital e das políticas públicas balizadas pelo atual momento, são elementos na ordem de discussão. Colocamos como uma urgente necessidade o pensar as identidades em formação e reconfiguração e os usos destas num contexto social em que é mais urgente ainda o descortinar das utopias e esperanças numa transformação social efetiva e radical.

\section{REFERÊNCIAS BIBLIOGRÁFICAS}

ABREU, Mauricio de Almeida. A evolução urbana do Rio de Janeiro. Rio de Janeiro: IPP, 2006.

ANTUNES, Ricardo. Adeus ao Trabalho - ensaio sobre as metamorfoses e a centralidade do mundo do trabalho. São Paulo: Cortez, 1995. Os sentidos do trabalho. São Paulo: Boitempo, 1999.

CABRAL, M. S. A. Multiculturalismo. Rio de Janeiro: DP\&A, 1999.

CARVALHO, José Murilo. Os bestializados: o Rio de Janeiro e A República que não foi. São Paulo: Companhia das Letras, 1987.

ELIAS, Norbert. A sociedade dos indivíduos. Rio de Janeiro, Jorge Zahar Editor, 1994.

FRAIHA, Silvia e LOBO, Tiza. Bairros do Rio: Ramos, Olaria e Penha. Rio de Janeiro: Editora Fraiha, s/d. 
FRIGOTTO, Gaudêncio. Fazendo pelas mãos a cabeça do trabalhador: o trabalho como elemento pedagógico na formação profissional. Cadernos de Pesquisa, n.47, nov. 1983.

Educação e crise do capitalismo real. São Paulo: Cortez, 1995.

(Org.) Educação e Crise do Trabalho: perspectivas de final de século.

Petrópolis: Vozes, 1998

GODINHO, Floriano. Reestruturação produtiva, território de poder no Rio de Janeiro. Rio de Janeiro: Garamond, 2008.

GONÇALVES, Rafael Soares. A construção jurídica das favelas do Rio de Janeiro: das origens ao Código de obras de 1937 [on-line] In: OS URBANITAS - Revista de Antropologia Urbana. Ano 4, vol.4, n.5, fevereiro de 2007. Disponível via http://www.osurbanitas.org/osurbanitas5/, 2007. Capturado em 10/01/2009.

GRAMSCI, A. Concepção Dialética da História. Rio de Janeiro: Civilização Brasileira, 1991

. Os intelectuais e a organização da Cultura. Rio de Janeiro: Civilização Brasileira, 1982.

Cadernos do Cárcere. Volume 4 (americanismo e fordismo). Rio de Janeiro: Civilização Brasileira, 2001.

HALL, Stuart. A identidade cultural na pós-modernidade. Rio de Janeiro; DP \& A, 2000.

HARDMAN, Foot e LEONARDI, Vitor. História da Indústria e do Trabalho no Brasil. São Paulo: Ática, 1990.

HARVEY, David. Condição pós-moderna: Uma pesquisa sobre as origens da mudança cultural. (12a ed.). São Paulo: Loyola, 2003.

KOSIK, Karel. Dialética do Concreto. São Paulo: Paz e Terra, 2002.

KOWARICK, Lucio. A espoliação urbana. Paz e terra, Rio de Janeiro, 1993

KUENZER, Acácia. A pedagogia da fábrica: as relações de produção e a educação do trabalhador. São Paulo: Cortez/Autores Associados, 1985.

Desafios teórico-metodológicos da relação trabalho-educação. In: 
Educação e Crise do Trabalho: perspectivas de final de século. Petrópolis: Vozes, 1998

LAURELL, Asa Cristina. Avançando em direção ao passado: a política social do neoliberalismo. In.: Laurell, Asa Cristina (org.) Estado e políticas sociais no neoliberalismo. São Paulo: Cortez, 1995.

MARX , Karl. Prefácio. Para crítica da economia política. Salário, preço e lucro. O rendimento e suas fontes: a economia vulgar. São Paulo: Abril Cultural, 1982.

Capítulo $6^{\circ}$ inédito d'O Capital: Resultados do processo de produção imediato. Porto (Portugal): Publicações Escorpião, 1975.

RUMMERT, S. M. Educação e Identidade dos Trabalhadores: concepções do capital e do trabalho. São Paulo: Xamã; Niterói: Intertexto, 2000.

Aspirações, interesses e identidade dos trabalhadores: elementos essenciais à construção da hegemonia. In: Trabalho Necessário, Revista Eletrônica do NEDDATE/UFF, ano 2, n. 2, 2004. Disponível em www.uff.br/trabalhonecessario. Acesso em 20/09/2009.

SENNETT, Richard. A corrosão do caráter. conseqüências pessoais do trabalho no novo capitalismo. (4 ed.). Rio de Janeiro: Record, 2000.

SOARES, Laura Tavares. Os custos do ajustes neoliberal na América Latina. São Paulo: Cortez, 2002.

TIRIBA, Lia. Economia Popular e cultura do trabalho: pedagogia(s) da produção associada. Ijuí: Editora Unijuí, 2001.

TIRIBA, Lia; PICANÇO, Iracy. Trabalho e educação.Arquitetos abelhas e outros tecelões da economia popular solidária. Aparecida: Idéias e letras, 2004.

WOOD, Ellen Meiksins. A origem do capitalismo. Rio de Janeiro: Jorge Zahar, 2001.

\footnotetext{
${ }^{1}$ Atualmente, o nome "morro", para além de designar um acidente geográfico ou um espaço geográfico, figura na mídia e no uso popular com a mesma conotação de "favela", portanto, locais marcados por regras próprias e pela ausência de civilidade. No lugar de favela tal, usa-se "morro tal", como se o conjunto geográfico dos morros do Rio de Janeiro, tornando-se completamente ocupado pelas populações mais pobres tornam-se sinônimo de favela.

${ }^{2}$ A cidade até então era dividida por núcleo central, periferia imediata, periferia intermediária e periferia distante. A periferia imediata abrangia a região de Jacarepaguá, Valqueire, Lins, Cascadura, Engenho de Dentro, Madureira, Marechal Hermes, Vila da Penha, Penha, Brás de Pina, Cordovil, Ramos, Olaria, Bonsucesso e adjacências (Abreu, op. cit, p. 21).
} 
${ }^{3}$ O Prefeito Pedro Ernesto (década de 1930) deu um tratamento diferenciado às favelas. De acordo com Gonçalves (op. cit.) "o prefeito visitou frequentemente as favelas, acolhendo as reinvidicações formuladas pelos 'centros de melhoramentos' que se formavam em várias delas, nesta época. Duas medidas implementadas por esta administração são ricas de simbolismo e revelam a profunda mudança da política pública em relação às favelas. Primeiramente, foi a instalação de certos serviços e equipamentos no interior de algumas favelas. Esta medida tanto aceitava como legítimas as reinvidicações desta população como reconhecia oficialmente as favelas como partes integrantes da cidade. A célebre reforma educacional, implementada pela prefeitura, abriu o sistema educacional para os favelados, construindo inúmeras escolas públicas perto das favelas e, pela primeira vez, construindo uma dentro de uma favela, a Escola Pública Humberto de Campos, no Morro da Mangueira. Em segundo lugar, a prefeitura procurou intervir nos diversos conflitos fundiários, evitando remoções e despejos impetrados contra os favelados e abolindo as remoções violentas de anos anteriores. Observamos, assim, uma conjuntura social favorável ao reconhecimento das demandas da população favelada. Apesar da ausência de instrumentos jurídicos eficazes contra as remoções, os favelados ja demonstravam um pleno conhecimento das engrenagens jurídico-políticas. Sem descartar os meios legais e judiciais, os favelados procuravam frequentemente o apoio da imprensa, evocando as consequências sociais nefastas que uma possível remoção provocaria. Diante do dilema de se aplicar a lei literalmente ou reconhecer as reivindicações sociais dos favelados, o juiz normalmente recorria ao poder executivo na esperança da promulgação de um decreto de desapropriação, que 'congelaria' assim a disputa. Estas negociações políticas permitiam a permanência precária dos favelados, já que muitos desses processos vão se arrastar por anos e décadas” (p.13).

${ }^{4}$ Pesquisa feita por Abreu (2006) com respeito à evolução urbana do Rio de Janeiro traz dados do recenseamento de 1920 apontando esta região como o segundo maior contingente de trabalhadores na incipiente indústria da Cidade.

${ }^{5}$ Ver pesquisa "Rumo à Nova América. Pós-modernismo, trabalho e educação superior no subúrbio do Rio de Janeiro", de José Rodrigues (UFF). Um texto inicial publicado sobre a chegada de uma universidade ao referido shopping pode ser lido em www.uff.br/trabalhonecessario, sob o título "a universidade vai ao shopping center". 